\title{
ITRAQ Proteomic Analysis of Yellow and Black Skin in Jinbian Carp (Cyprinus carpio)
}

\author{
Xiangchen Ye ${ }^{1}$, Lingling Zhou ${ }^{2}$, Jingyi Jia ${ }^{2}$, Lingjing Wei ${ }^{1}$, Yanhong Wen ${ }^{3}$, Xueyu Yan ${ }^{1}$, \\ Jie Huang ${ }^{3}$, Baojiang Gan ${ }^{1}$, Kang Liu ${ }^{1}$, Yejian $\mathrm{Lv}^{1, *}$ and Guangfu $\mathrm{Hu}^{2, *}$ \\ 1 Aquatic Species Introduction and Breeding Center of Guangxi, Nanning 530031, China; \\ chen-chen79@163.com (X.Y.); ljwei9012@163.com (L.W.); yanxueyu@bbgu.edu.cn (X.Y.); \\ ganbaojiangvip@126.com (B.G.); liukande1988@163.com (K.L.) \\ 2 College of Fisheries, Huazhong Agricultural University, Wuhan 430070, China; 1lz9872@163.com (L.Z.); \\ Jiajy94@163.com (J.J.) \\ 3 Extension Station of Fisheries Technology of Liuzhou, Liuzhou 545006, China; \\ Wenyanhong888@163.com (Y.W.); huangjiexd@126.com (J.H.) \\ * Correspondence: lvyejian1004@126.com (Y.L.); huguangfu@mail.hzau.edu.cn (G.H.); \\ Tel.: +86-13517266892 (G.H.)
}

Received: 28 July 2020; Accepted: 24 September 2020; Published: 30 September 2020

check for updates

\begin{abstract}
Colors are important phenotypic traits for fitness under natural conditions in vertebrates. Previous studies have reported several functional genes and genetic variations of pigmentation, but the formation mechanisms of various skin coloration remained ambiguous in fish. Jinbian carp, a common carp variant, displays two colors (yellow and black) in the skin, thus, it is a good model for investigating the genetic basis of pigmentation. In the present study, using the Jinbian carp as model, isobaric tags for relative and absolute quantification (ITRAQ) proteomics analysis was performed for yellow and black skin, respectively. The results showed that 467 differentially expressed proteins (DEPs) were identified between the yellow skin and the black skin. Similar to mammals, the up-regulated DEPs in black skin included UV excision repair protein RAD23 homolog A (Rad23a), melanoregulin (mreg), 5,6-dihydroxyindole-2-carboxylic acid oxidase5 (tyrp1) and melanocyte protein PMEL (PMEL), which were mainly grouped into melanogenesis pathway. However, several up-regulated DEPs in yellow skin were mainly enriched in nucleotide metabolism, such as GTPase IMAP family member 5 (GIMAP5), AMP deaminase 1 (AMPD1), adenosylhomocysteinase $b$ (ahcy-b), and pyruvate kinase (PKM). In summary, several candidate proteins and their enrichment pathways for color variation in Jinbian carp were identified, which may be responsible for the formation of different colorations.
\end{abstract}

Keywords: pigmentation; ITRAQ; Jinbian carp; melanin; pteridine

\section{Introduction}

Colors are important phenotypic traits for fitness under natural conditions in vertebrates [1]. Skin coloration is the result of diverse pigments synthesized by chromatophores, which is affected by several factors, including environmental, nutritional, physiological, and genetic conditions. Among them, the genetic basis of skin pigmentation is the most fundamental and important factor. Therefore, several studies have been devoted to examine the genetic basis of pigmentation in animals. Previous studies have found that many biological pathways and genes were involved in the pigment synthesis, including melanin and pteridine synthesis pathway [2].

In teleost, several chromatophores have been identified, which played an important role in the formation of variety coloration, including melanophores (melanin granules), xanthophores (pteridine or carotenoid granules), iridophores (guanine), leucophores, and erythrophores (carotenoids and 
pteridine) [3-6]. Using teleost as models, several studies have tried to examine the genetic variation among different colored skin. Haffter et al. observed that dominant mutations in genes could change the pigment pattern in adult zebrafish [7]. However, the key genes and biological processes, which are involved in the combination of different colors, are still ambiguous.

Common carp (Cyprinus carpio L.) was the most widely cultivated freshwater fish in the world. In China, common carp has been farmed for more than 2500 years [8,9]. During the long farming history, common carp has evolved several variants, which was caused by geographic isolation and natural as well as human selection pressures [10]. In China, several variants have also been developed in the regional distribution and cultivation zones over thousands of years. Among them, Jinbian carp is an important variant for paddy-field fish culture in China, which appears with two yellow stripes on both sides of its dorsal fin [11]. Due to its variable colors, Jinbian carp is a good system for studying color pattern polymorphism.

In this study, isobaric tags for relative and absolute quantification (ITRAQ) analysis was used to examine the proteomic variations between yellow skin and black skin in Jinbian carp. The aims of our present study were to: (i) provide an overview of the proteome in yellow skin and black skin; (ii) identify differentially expressed proteins (DEPs) that were possibly involved in yellow coloration; (iii) examine the expression levels of key proteins in the melanin and pteridine pathways between two skin colors.

\section{Materials and Methods}

\subsection{Sample Preparation}

The common carp (with black skin only) and the manually selected Jinbian common carp (with yellow and black skin) (Figure 1) were collected from Aquatic Species Introduction and Breeding Center of Guangxi, Nanning, China. The yellow skin (Y) and black skin (B) were collected from the same Jinbian carp. In addition, the black skin in the wild common carp (W) was also collected. All the samples in the cryogenic vials were immediately frozen in liquid nitrogen and stored at $-80^{\circ} \mathrm{C}$ until further processing. All animal experiments were conducted in accordance with the guidelines and approval of the respective Animal research and Ethics committees of Huazhong Agricultural University (Ethical Approval No. HBAC20091138; Date: 15 November 2009).
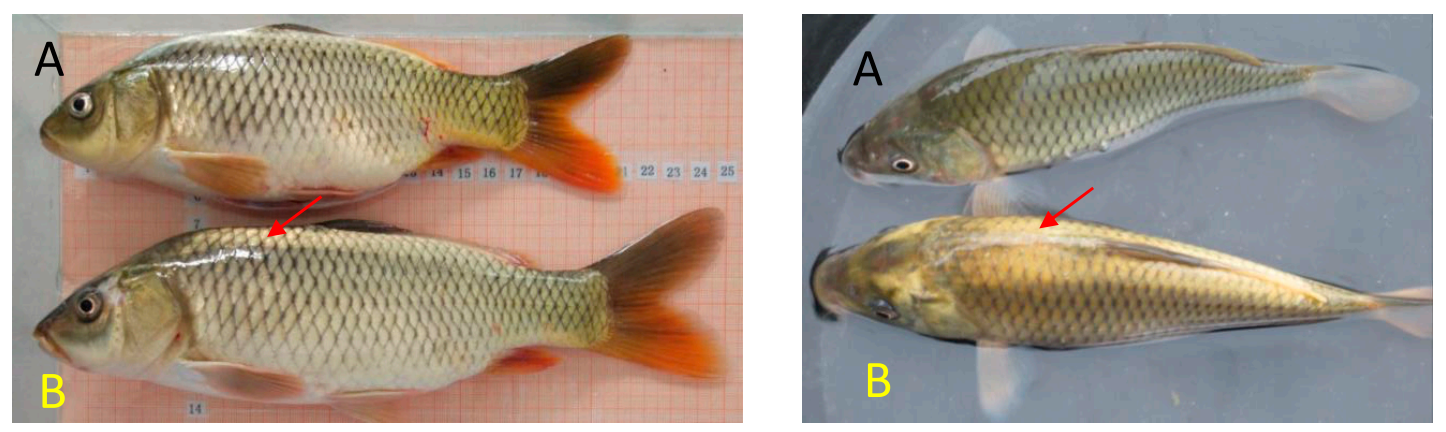

Figure 1. Photographs of the wild common carp (A) and Jinbian carp (B).

\subsection{Protein Preparation and $i T R A Q$ Labeling}

The skin samples were put into the lysis buffer (8 M urea, $0.3 \%$ SDS) with protease inhibitors (Thermo, Rockford, IL, USA), and were then sonicated in ice. The protein samples were reduced with DTT $(10 \mathrm{mM})$ at $56^{\circ} \mathrm{C}$ for $1 \mathrm{~h}$, then the IAM $(55 \mathrm{mM})$ were used to alkylate the samples in the darkroom for $1 \mathrm{~h}$. The reduced and alkylated protein mixtures were precipitated by adding $4 \times$ volume of chilled acetone at $-20^{\circ} \mathrm{C}$ overnight. After centrifugation at $4{ }^{\circ} \mathrm{C}$ with $30,000 \times g$, the pellet was dissolved in $0.5 \mathrm{M}$ TEAB (Applied Biosystems, Milan, Italy) and sonicated in ice. After centrifugation at $4{ }^{\circ} \mathrm{C}$ with $30,000 \times g$, an aliquot of the supernatant was taken to determine the protein concentration with 
a 2-D Quant Kit (GE Healthcare). The proteins in the supernatant were kept at $-80{ }^{\circ} \mathrm{C}$ for further analysis. The proteins were digested with modified trypsin at $37^{\circ} \mathrm{C}$ overnight and then labeled with different iTRAQ reagents according to the manufacturer's instruction. The labeled reagent was dissolved in acetonitrile, mixed with the peptides, and then incubated at room temperature for $2 \mathrm{~h}$. The labeled samples were then mixed, desalted, and vacuum-dried. More details for iTRAQ labeling were provided in our previous studies [12].

\subsection{Liquid Chromatography Tandem Mass Spectrometry (LC/LC-MS/MS) Analysis}

Each fraction was resuspended with loading buffer $(5 \mathrm{mM}$ ammonium formate containing $2 \%$ acetonitrile; $\mathrm{pH}=10$ ) and separated by high-pH reversed-phase liquid chromatography (RPLC, Acquity Ultra Performance LC; Waters, Milford, MA, USA). The solvent A and solvent B was $2 \%$ ACN ( $\mathrm{pH}=10$, adjusted by ammonia) and $80 \% \mathrm{ACN}(\mathrm{pH}=10$, adjusted by ammonia), respectively. The gradient elution was performed with $0-30 \%$ solvent $\mathrm{B}$ for $2-38 \mathrm{~min}$ and $30-100 \%$ solvent B for 38-40 min on a high-pH RPLC column $(\mathrm{C} 18,1.7 \mu \mathrm{m}, 2.1 \mathrm{~mm} \times 150 \mathrm{~mm}$; Waters Corporation, Milford, MA, USA). All mass spectrometry proteomics data were deposited in Integrated Proteome Resources (iProX, http://www.iprox.org/; project ID: IPX0002447000; ProteomeXchange ID: PXD021293).

\subsection{Analysis of the Identified Proteins}

By using Proteome Discoverer ${ }^{\mathrm{TM}}$ Software 2.1 (Thermo, Rockford, IL, USA), the raw data obtained from LC/LC-MS/MS analysis were processed. The proteins were annotated with the Blast2GO (Gene Ontology) program against the nonredundant protein database (NR; NCBI) (https://www.blast2go.com/). The transcriptome data from black and yellow skin of Jinbian carp as well as black skin of common carp was also used as a reference database for protein annotation. In addition, the differentially expressed proteins (DEPs) were further assigned to the Kyoto Encyclopedia of Genes and Genomes (KEGG) database (KEGG; http://www.genome.jp/kegg/). The hypergeometric distribution was used for the GO and KEGG pathway enrichment analysis, and Fisher's exact test was used for accurate test, and Benjamini was used for the correction of multiple tests. In this analysis, the threshold of significant enrichment of GO function and KEGG pathway of DEPs was $p$-value $<0.05$. The $p$-value of the significant difference between the samples was calculated by using the $t$-test in the $R$ language. For identifying significantly up- or down-regulated proteins ( $p$-value $<0.05)$, the threshold values of $\mathrm{Y} / \mathrm{B}$ or $\mathrm{Y} / \mathrm{W}$ ratios were $\geq 1.50$ or $\leq 0.67$ ( $\geq 1.5$-fold), respectively.

\section{Results}

\subsection{Protein Identification and Quantitation}

The iTRAQ analysis revealed that 8064 protein hits were detected in the common carp skin by Proteome Discover (Supplementary Table S1). The error in the matching of the peptide segment detected in the database was below 0.05 Da (Figure 2A). As shown in Figure 2B, the peptide length was around in 9-30 aa, and most of peptide segments were enriched in 9-16 aa length. The numbers of peptides identified into the proteins was exhibited in Figure $2 \mathrm{C}$, which showed that the coverage of most protein sequence was at $1-40 \%$. In addition, the molecular weight of most proteins was $11-150 \mathrm{kDa}$ (Figure 2E). 


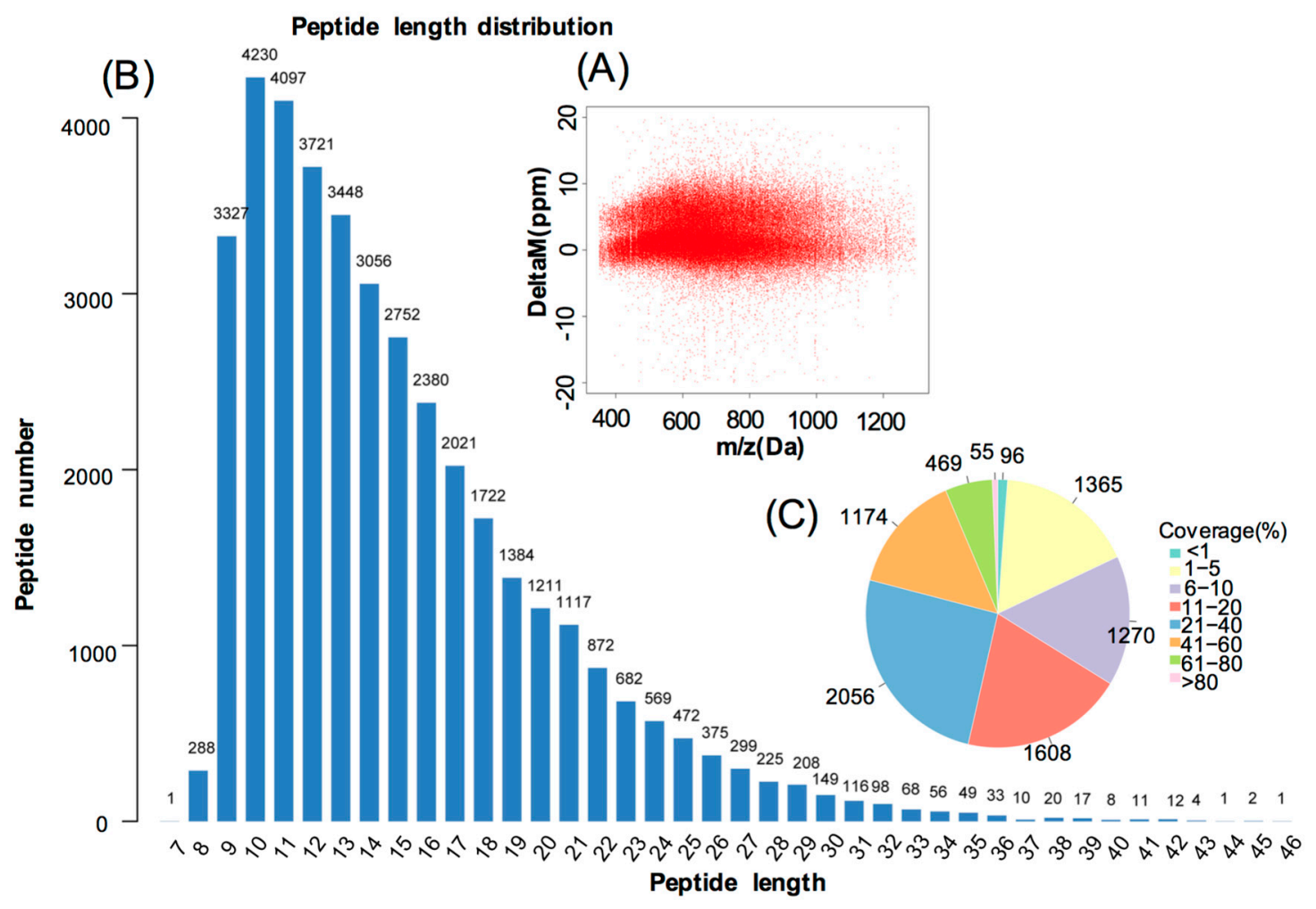

(D)

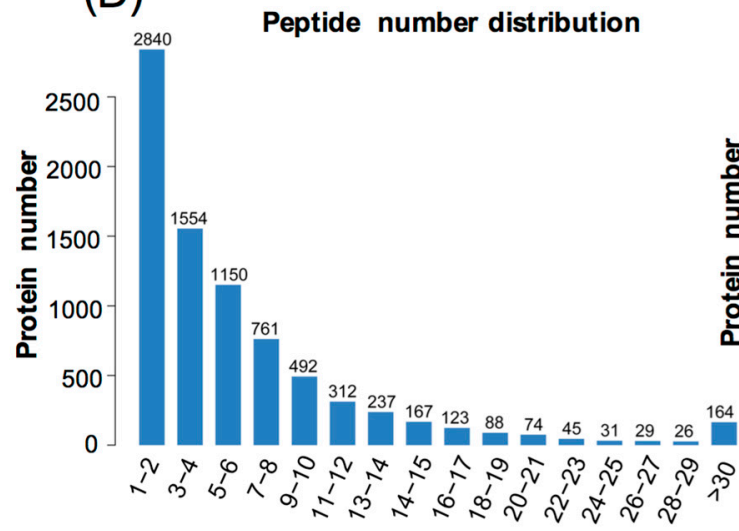

Peptide number
(E)

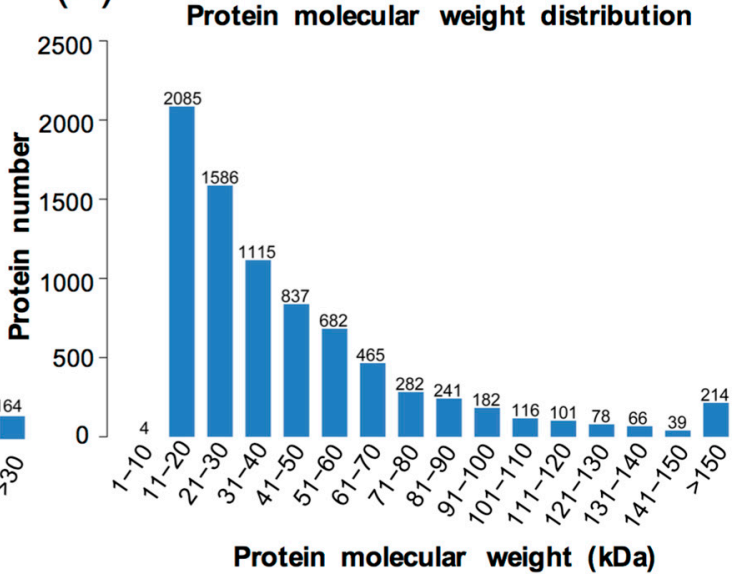

Figure 2. Identification and analysis of the proteome in yellow skin in Jinbian carp (Y), black skin in Jinbian carp (B) and black skin in wild common carp (W). (A) Distribution of peptide segment matching error. (B) The distribution of peptide length. The $x$-axis indicates the length of the peptide, and the $y$-axis indicates the number of peptides of the corresponding length. (C) The coverage distribution of identified proteins. Each fan represents the proportion of a range of coverage. The larger the fan area, the more proteins covered in this range. The number outside the fan indicates the number of proteins covered in this range. (D) The distribution of peptide number. The $x$-axis indicates the number of peptides covering the protein, and the $y$-axis indicates the number of proteins. (E) The distribution of protein molecular weight. The $x$-axis shows the size of the identified protein molecular weight (unit: kilodalton, $\mathrm{kDa}$ ), and the $\mathrm{y}$-axis represents the number of identified proteins reflecting the corresponding size.

\subsection{Identification and GO Classification of the Proteins in Common Carp Skin}

The annotated proteins were enriched in three GO categories, including biological function, molecular function, and cellular component (Figure 3A). In the molecular functions, most proteins in 
common carp skins were enriched in the binding (511 proteins), catalytic (336), structural molecule (85), transporter (38), and antioxidant activities (seven). In the cellular component, common carp skin proteins were enriched in the categories of cell part (478 proteins), protein-containing complex (287), organelle part (234), membrane part (94), extracellular region part (45), supramolecular complex (30), and membrane-enclosed lumen (two). The most represented biological functions included the categories of cellular process (426 proteins), metabolic process (267), and biological regulation (241). Other important biological function allocations included the developmental process (145 proteins), cellular component organization (137), localization (126), response to stimulus (84), and multicellular organismal process (62).

A

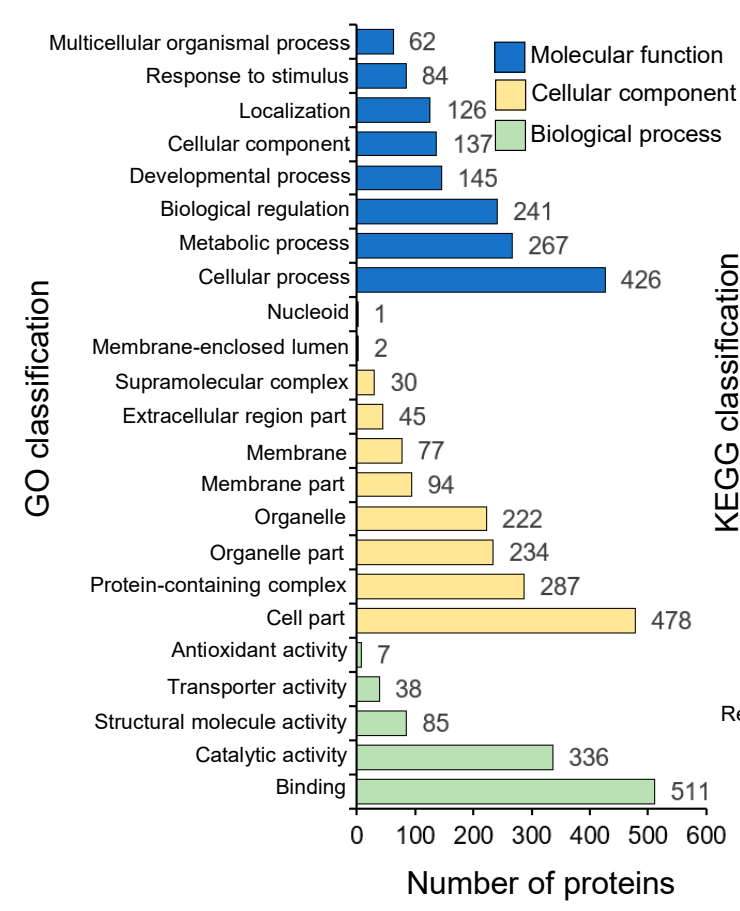

B

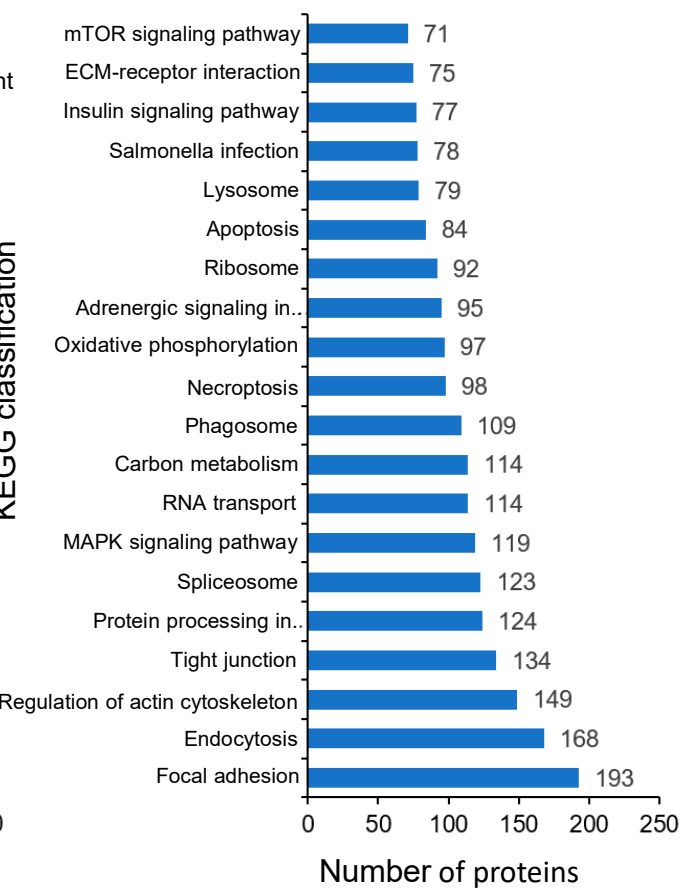

Figure 3. GO (Gene Ontology) (A) and KEGG (Kyoto Encyclopedia of Genes and Genomes) (B) analyses of the proteins derived from common carp skins.

Total of 2193 proteins were enriched in 159 pathways. The top 20 pathway ontologies were shown in Figure 3B. Proteins were most enriched in relation to focal adhesion (193 proteins), endocytosis (168), regulation of actin cytoskeleton (149), tight junction (134), protein processing in endoplasmic reticulum (124), spliceosome (123), MAPK signaling pathway (119), RNA transport (114), Carbon metabolism (114), phagosome (109), necroptosis (98), oxidative phosphorylation (97), adrenergic signaling in cardiomyocytes (95), ribosome (92), apoptosis (84), lysosome (79), salmonella infection (78), insulin signaling pathway (77), ECM-receptor interaction (75), and mTOR signaling pathway (71).

\subsection{Identification of Differentially Expressed Proteins (DEPs) between Yellow and Black Skin in Jinbian Carp}

A total of 467 DEPs were identified between yellow $(\mathrm{Y})$ and black (B) skin derived from the same Jinbian carp $(\mathrm{FC} \geq 1.2$ and $p$-value $<0.05)$ (Figure $4 \mathrm{~A}$ ), including 94 up-regulated proteins (Table 1) and 373 down-regulated proteins (Table 2) in yellow skin. GO analysis showed that most up-regulated DEPs in yellow skin were preferentially involved in metabolic process, transporter activity, catalytic activity, membrane part, biological regulation, organelle, cellular process, and binding (Figure 5A). Additionally, most down-regulated DEPs in yellow skin compared to black skin were mainly grouped into biological regulation, transporter activity, organelle part, protein-containing 
complex, cellular component biogenesis, binding, cellular process, metabolic process, organelle, catalytic activity, and cell part (Figure 5B).

Table 1. The up-regulated differentially expressed proteins (DEPs) in black skin (B) compared to yellow skin (Y).

\begin{tabular}{|c|c|c|c|c|}
\hline Uniprot_ID & Gene & Description & $\mathrm{FC}(\mathrm{B} / \mathrm{Y})$ & $p$ Value \\
\hline MLRB_CHICK & $N / A$ & Myosin regulatory light chain 2B & 6.34 & 0.0029041 \\
\hline MYL4_HUMAN & MYL4 & Myosin light chain 4 & 5.22 & 0.0035055 \\
\hline TNNT2_CHICK & TNNT2 & Troponin $\mathrm{T}$ & 4.44 & 0.0005641 \\
\hline MYPC3_CHICK & MYBPC3 & Myosin-binding protein C & 4.16 & $7.544 \times 10^{-5}$ \\
\hline TNNT3_HUMAN & TNNT3 & Troponin T & 4.01 & 0.0049163 \\
\hline TNNI1_HUMAN & TNNI1 & Troponin I & 3.53 & $2.086 \times 10^{-5}$ \\
\hline MYH7_HUMAN & MYH7 & Myosin-7 & 3.53 & 0.0402934 \\
\hline AT2A1_MAKNI & atp2a1 & $\begin{array}{c}\text { Sarcoplasmic/endoplasmic reticulum } \\
\text { calcium ATPase } 1\end{array}$ & 3.28 & 0.0028990 \\
\hline TPM1_LIZAU & $N / A$ & Tropomyosin alpha-1 chain & 3.27 & 0.0002662 \\
\hline TNNI3_XENLA & tnni3 & Troponin I & 3.22 & 0.0001500 \\
\hline COX42_THUOB & $N / A$ & $\begin{array}{l}\text { Cytochrome c oxidase subunit } 4 \\
\text { isoform } 2\end{array}$ & 3.11 & 0.0014771 \\
\hline TNNI1_MOUSE & Tnni1 & Troponin I & 3.03 & 0.0042539 \\
\hline ACTN4_CHICK & ACTN4 & Alpha-actinin-4 & 2.82 & 0.0037840 \\
\hline ACTN2_CHICK & ACTN2 & Alpha-actinin-2 & 2.75 & 0.0009886 \\
\hline HHATL_HUMAN & HHATL & $\begin{array}{l}\text { Protein-cysteine N-palmitoyltransferase } \\
\text { HHAT-like protein }\end{array}$ & 2.71 & 0.0062292 \\
\hline MYPC1_HUMAN & MYBPC1 & Myosin-binding protein C & 2.61 & 0.0433731 \\
\hline NNTM_HUMAN & NNT & NAD $(\mathrm{P})$ transhydrogenase & 2.50 & 0.0009916 \\
\hline KCRB_CHICK & $C K B$ & Creatine kinase B-type & 2.48 & 0.0016669 \\
\hline PYGM_MACFA & PYGM & Glycogen phosphorylase & 2.36 & 0.0038506 \\
\hline IDHP_MACFA & $\mathrm{IDH} 2$ & Isocitrate dehydrogenase [NADP] & 2.34 & 0.0043346 \\
\hline AT2A2_CHICK & ATP2A2 & $\begin{array}{c}\text { Sarcoplasmic/endoplasmic reticulum } \\
\text { calcium ATPase } 2\end{array}$ & 2.30 & 0.0008799 \\
\hline ACTC_RAT & Actc1 & Actin & 2.27 & 0.0071161 \\
\hline AATM_RAT & Got2 & Aspartate aminotransferase & 2.25 & 0.0006509 \\
\hline MYH7_PIG & MYH7 & Myosin-7 & 2.22 & 0.0386928 \\
\hline UCRI_AOTAZ & UQCRFS1 & $\begin{array}{c}\text { Cytochrome b-c1 complex subunit } \\
\text { Rieske }\end{array}$ & 2.15 & 0.0031625 \\
\hline SRCA_MOUSE & Srl & Sarcalumenin & 2.09 & 0.0002984 \\
\hline NEBU_HUMAN & $N E B$ & Nebulin & 1.96 & 0.0014726 \\
\hline ECHA_MOUSE & Hadha & Trifunctional enzyme subunit alpha & 1.96 & 0.0102789 \\
\hline NDUA4_DANRE & ndufa4 & Cytochrome c oxidase subunit NDUFA4 & 1.96 & 0.0069833 \\
\hline MYH6_MOUSE & Myh6 & Myosin-6 & 1.93 & 0.0204875 \\
\hline MYH7_MOUSE & Myh7 & Myosin-7 & 1.91 & 0.0294791 \\
\hline COX5A_MOUSE & $\operatorname{Cox} 5 a$ & Cytochrome c oxidase subunit 5A & 1.90 & 0.0003158 \\
\hline MYH7_HORSE & MYH7 & Myosin-7 & 1.84 & 0.0194304 \\
\hline MDHM_FRAAN & $M M D H I$ & Malate dehydrogenase & 1.82 & 0.0010926 \\
\hline
\end{tabular}


Table 1. Cont.

\begin{tabular}{|c|c|c|c|c|}
\hline Uniprot_ID & Gene & Description & $\mathrm{FC}(\mathrm{B} / \mathrm{Y})$ & $p$ Value \\
\hline GLYM_RABIT & SHMT2 & Serine hydroxymethyltransferase & 1.82 & 0.0453498 \\
\hline DESM_PIG & $D E S$ & Desmin & 1.79 & 0.0065272 \\
\hline ATPA_PIG & ATP5F1A & ATP synthase subunit alpha & 1.78 & 0.0011789 \\
\hline ATP5J_PONAB & ATP5J & ATP synthase-coupling factor 6 & 1.77 & 0.0148907 \\
\hline ACSL1_CAVPO & ACSL1 & Long-chain-fatty-acid-CoA ligase 1 & 1.75 & 0.0038413 \\
\hline MYO6_CHICK & MYO6 & Unconventional myosin-VI & 1.75 & 0.0009482 \\
\hline CISY_DANRE & CS & Citrate synthase & 1.73 & 0.0008091 \\
\hline KPYM_CHICK & PKM & Pyruvate kinase PKM & 1.71 & 0.0122511 \\
\hline UCRI_MOUSE & Uqcrfs1 & $\begin{array}{c}\text { Cytochrome b-c1 complex subunit } \\
\text { Rieske }\end{array}$ & 1.70 & 0.0031496 \\
\hline ACADM_RAT & Acadm & $\begin{array}{l}\text { Medium-chain specific acyl-CoA } \\
\text { dehydrogenase }\end{array}$ & 1.70 & 0.0438522 \\
\hline SYPH_MOUSE & Syp & Synaptophysin & 1.70 & 0.0041077 \\
\hline AT5F1_PONAB & ATP5F1 & ATP synthase $\mathrm{F}(0)$ complex subunit B1 & 1.69 & 0.0064455 \\
\hline ADT3_BOVIN & SLC25A6 & ADP/ATP translocase 3 & 1.69 & 0.0150770 \\
\hline NLS1B_DANRE & $m f s d 2 a b$ & $\begin{array}{l}\text { Sodium-dependent } \\
\text { lysophosphatidylcholine symporter 1-B }\end{array}$ & 1.68 & 0.0272424 \\
\hline ECHA_RAT & Hadha & Trifunctional enzyme subunit alpha & 1.67 & 0.0027369 \\
\hline ADT2_BOVIN & SLC25A5 & ADP/ATP translocase 2 & 1.66 & 0.0289562 \\
\hline ACON_BOVIN & ACO2 & Aconitate hydratase & 1.66 & 0.0006630 \\
\hline KCNV1_BOVIN & KCNV1 & $\begin{array}{l}\text { Potassium voltage-gated channel } \\
\text { subfamily V member } 1\end{array}$ & 1.65 & 0.0236049 \\
\hline PGAM2_HUMAN & PGAM2 & Phosphoglycerate mutase 2 & 1.64 & 0.0458743 \\
\hline ECHB_MACFA & $H A D H B$ & Trifunctional enzyme subunit beta & 1.64 & 0.0153694 \\
\hline NDUAA_HUMAN & NDUFA10 & $\begin{array}{l}\text { NADH dehydrogenase [ubiquinone] } 1 \\
\text { alpha subcomplex subunit } 10\end{array}$ & 1.64 & 0.0027091 \\
\hline ADT1_BOVIN & $S L C 25 A 4$ & $\mathrm{ADP} / \mathrm{ATP}$ translocase 1 & 1.64 & 0.0373976 \\
\hline NDUS4_HUMAN & NDUFS4 & $\begin{array}{l}\text { NADH dehydrogenase [ubiquinone] } \\
\text { iron-sulfur protein } 4\end{array}$ & 1.61 & $1.724 \times 10^{-5}$ \\
\hline MYOZ2_PONAB & MYOZ2 & Myozenin-2 & 1.60 & 0.0020216 \\
\hline
\end{tabular}

Table 2. The up-regulated DEPs in yellow skin (Y) compared to black skin (B).

\begin{tabular}{ccccc}
\hline Uniprot_ID & Gene & Description & FC(Y/B) & $p$ Value \\
\hline FXR2_HUMAN & FXR2 & Fragile X mental retardation syndrome-related & 5.18 & 0.0018055 \\
& protein 2 & Myosin-binding protein C & 3.99 & 0.0101018 \\
\hline MYPC2_MOUSE & Mybpc2 & Tropomyosin alpha-1 chain & 3.21 & 0.0026475 \\
\hline TPM1_LIZAU & N/A & Parvalbumin-7 & 2.86 & 0.0203993 \\
\hline PRV7_DANRE & pvalb7 & Tropomyosin alpha-1 chain & 2.57 & 0.0042248 \\
\hline TPM1_XENLA & tpm1 & Centriolar coiled-coil protein of $110 \mathrm{kDa}$ & 2.45 & 0.0203727 \\
\hline CP110_HUMAN & CCP110 & Galectin-12 & 1.73 & 0.0051317 \\
\hline LEG12_HUMAN & LGALS12 & &
\end{tabular}


Table 2. Cont.

\begin{tabular}{|c|c|c|c|c|}
\hline Uniprot_ID & Gene & Description & $\mathrm{FC}(\mathrm{Y} / \mathrm{B})$ & $p$ Value \\
\hline H11_HUMAN & HIST1H1A & Histone H1.1 & 1.68 & 0.0206282 \\
\hline COCA1_MOUSE & Col12a1 & Collagen alpha- $1(\mathrm{XII})$ chain & 1.67 & 0.0363538 \\
\hline LEG4_BOVIN & LGALS4 & Galectin-4 & 1.66 & 0.0101980 \\
\hline TITIN_MOUSE & Ttn & Titin & 1.62 & 0.0323899 \\
\hline TITIN_HUMAN & TTN & Titin & 1.62 & 0.0486235 \\
\hline RHOG_HUMAN & RHOG & Rho-related GTP-binding protein RhoG & 1.59 & 0.0213023 \\
\hline COCA1_HUMAN & COL12A1 & Collagen alpha- $1(\mathrm{XII})$ chain & 1.56 & 0.0135574 \\
\hline CAHZ_DANRE & cahz & Carbonic anhydrase & 1.45 & 0.0387359 \\
\hline C2D1B_XENLA & $c c 2 d 1 b$ & Coiled-coil and $\mathrm{C} 2$ domain-containing protein $1 \mathrm{~B}$ & 1.43 & 0.0146113 \\
\hline PLPP1_CAVPO & PLPP1 & Phospholipid phosphatase 1 & 1.42 & 0.0265325 \\
\hline EIF1B_HUMAN & EIF1B & Eukaryotic translation initiation factor $1 \mathrm{~b}$ & 1.42 & 0.0201610 \\
\hline BRE1A_HUMAN & RNF20 & E3 ubiquitin-protein ligase BRE1A & 1.40 & 0.0237980 \\
\hline HCE1_ORYLA & hcea & High choriolytic enzyme 1 & 1.35 & 0.0377692 \\
\hline SPTB2_MOUSE & Sptbn1 & Spectrin beta chain & 1.34 & 0.0234210 \\
\hline HBB1_DANRE & $b a 1$ & Hemoglobin subunit beta-1 & 1.34 & 0.0356035 \\
\hline B3AT_ONCMY & $\operatorname{slc} 4 a 1$ & Band 3 anion exchange protein & 1.33 & 0.0495074 \\
\hline DMD_PIG & $D M D$ & Dystrophin & 1.33 & 0.0089534 \\
\hline AQP3_MOUSE & Aqp3 & Aquaporin-3 & 1.32 & 0.0099533 \\
\hline H3_DROME & His3 & Histone H3.2 & 1.32 & 0.0314604 \\
\hline MCM7_XENTR & $m c m 7$ & DNA replication licensing factor $\mathrm{mcm} 7$ & 1.32 & 0.0348232 \\
\hline H2B12_XENLA & $N / A$ & Histone H2B 1.2 & 1.31 & 0.0439092 \\
\hline NLRC3_HUMAN & NLRC3 & Protein NLRC3 & 1.31 & 0.0217364 \\
\hline GOLP3_MOUSE & Golph3 & Golgi phosphoprotein 3 & 1.30 & 0.0116354 \\
\hline TSP1_XENLA & thbs1 & Thrombospondin-1 & 1.30 & 0.0151795 \\
\hline PSA2_CARAU & psma2 & Proteasome subunit alpha type-2 & 1.29 & 0.0222874 \\
\hline FKBP5_HUMAN & FKBP5 & Peptidyl-prolyl cis-trans isomerase FKBP5 & 1.29 & 0.0071276 \\
\hline FLNC_RAT & Flnc & Filamin-C & 1.29 & 0.0458236 \\
\hline RALB_MACFA & $R A L B$ & Ras-related protein Ral-B & 1.26 & 0.0165614 \\
\hline CP3AA_MESAU & CYP3A10 & Lithocholate 6-beta-hydroxylase & 1.26 & 0.0305838 \\
\hline CD63_MOUSE & Cd63 & CD63 antigen & 1.25 & 0.0002011 \\
\hline ZYX_CHICK & $Z Y X$ & Zyxin & 1.24 & 0.0092652 \\
\hline CATL_SARPE & $N / A$ & Cathepsin L & 1.24 & 0.0087340 \\
\hline PTX3_MOUSE & Ptx3 & Pentraxin-related protein PTX3 & 1.23 & 0.0302834 \\
\hline CATZ_RAT & Ctsz & Cathepsin Z & 1.23 & 0.0072279 \\
\hline DYHC1_MOUSE & Dync1h1 & Cytoplasmic dynein 1 heavy chain 1 & 1.23 & 0.0327325 \\
\hline AR6P6_BOVIN & ARL6IP6 & $\begin{array}{l}\text { ADP-ribosylation factor-like protein 6-interacting } \\
\text { protein } 6\end{array}$ & 1.23 & 0.0445232 \\
\hline TPM3_MOUSE & Tpm3 & Tropomyosin alpha-3 chain & 1.23 & 0.0293024 \\
\hline TBD2B_MOUSE & $T b c 1 d 2 b$ & TBC1 domain family member $2 \mathrm{~B}$ & 1.22 & 0.0450312 \\
\hline NEBU_HUMAN & $N E B$ & Nebulin & 1.22 & 0.0288621 \\
\hline
\end{tabular}


Table 2. Cont.

\begin{tabular}{ccccc}
\hline Uniprot_ID & Gene & Description & FC(Y/B) & $p$ Value \\
\hline LSM3_MOUSE & Lsm3 & U6 snRNA-associated Sm-like protein LSm3 & 1.21 & 0.0099663 \\
\hline TXB1B_DANRE & tax1bp1b & Tax1-binding protein 1 homolog B & 1.21 & 0.0473674 \\
\hline HEPH_MOUSE & Heph & Hephaestin & 1.21 & 0.0252919 \\
\hline CAD26_HUMAN & CDH26 & Cadherin-like protein 26 & 1.21 & 0.0214089 \\
\hline NIBL1_HUMAN & FAM129B & Niban-like protein 1 & 1.21 & 0.0188033 \\
\hline CNN1_MUSPF & CNN1 & Calponin-1 & 1.21 & 0.0017860 \\
\hline
\end{tabular}

In addition to the GO analysis, KEGG pathway enrichment analysis was also used to further elucidate the putative functions of these DEPs. These results demonstrated that down-regulated proteins in yellow skin were mainly involved in the oxidative phosphorylation (53/142), carbon metabolism (33/142), cardiac muscle contraction (22/142), biosynthesis of amino acids (14), fatty acid metabolism (13), calcium signaling pathway (13), fatty acid degradation (13), citrate cycle (13), necroptois (12), propanoate metabolism (12), valine, leucine and isoleucine degradation (12), glycolysis/gluconeogenesis (11), adrenergic signaling in cardiomyocytes (11), cysteine and methionine metabolism (10), purine metabolism (two), biosynthesis of unsaturated fatty acids (8), beta-Alanine metabolism (eight), butanoate metabolism (eight), tryptophan metabolism (eight), cellular senescence (eight), lysine degradation (eight), starch and sucrose metabolism (eight), and fatty acid elongation (eight) (Figure 6A). In addition, the up-regulated proteins in yellow skin were enriched in the phagosome (5/21), lysosome (five), focal adhesion (three), salmonella infection (three), adrenergic signaling in cardiomyocytes (three), cardiac muscle contraction (three), apoptosis (three), mitophagy (two), and MAPK signaling pathway (one) (Figure 6A).
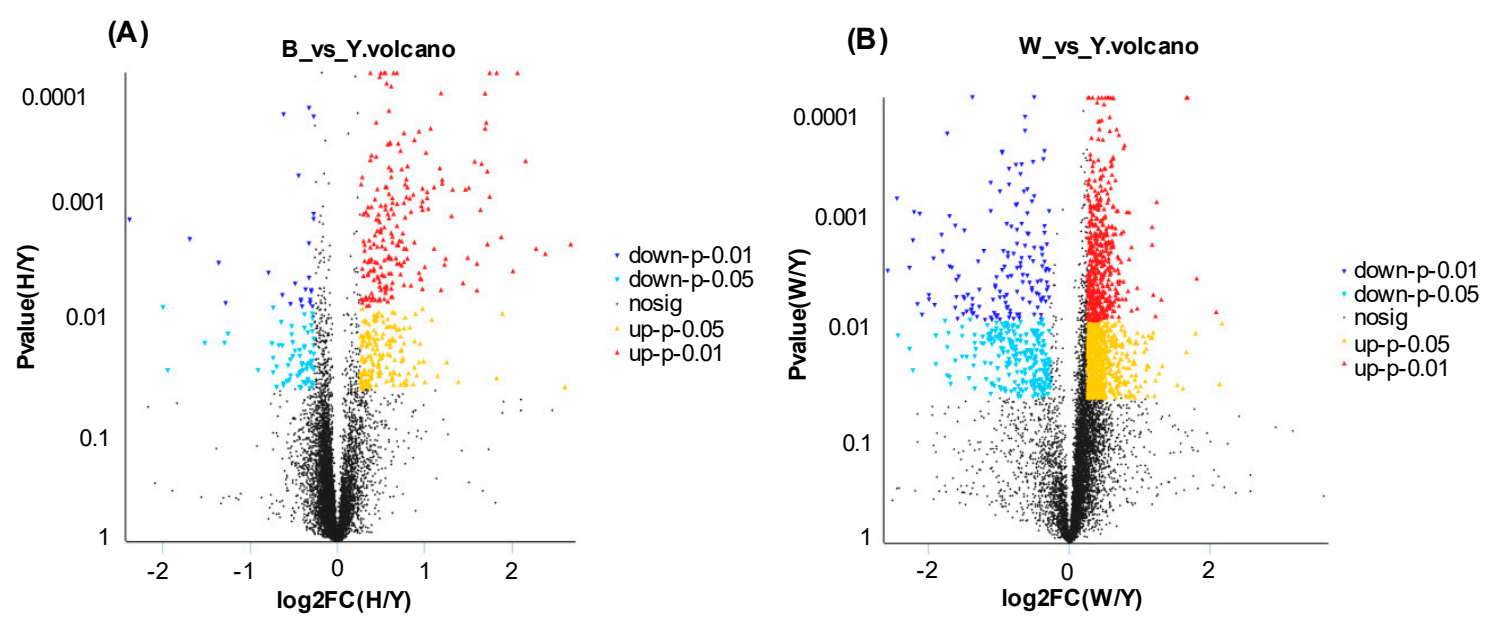

Figure 4. Volcano plot of DEPs in B, Y, and W. (A) Volcano plot of DEPs in B and Y. (B) Volcano plot of DEPs in W and Y. Splashes represent different genes, Yellow dots indicate proteins that are significantly up-regulated at $p<0.05$, red dots indicate proteins that are significantly up-regulated at $p<0.01$, light blue dots indicate proteins that are significantly down-regulated at $p<0.05$, blue dots indicate protein that are significantly down-regulated under $p<0.01$ conditions, and black spots are non-significantly differentially expressed proteins. 

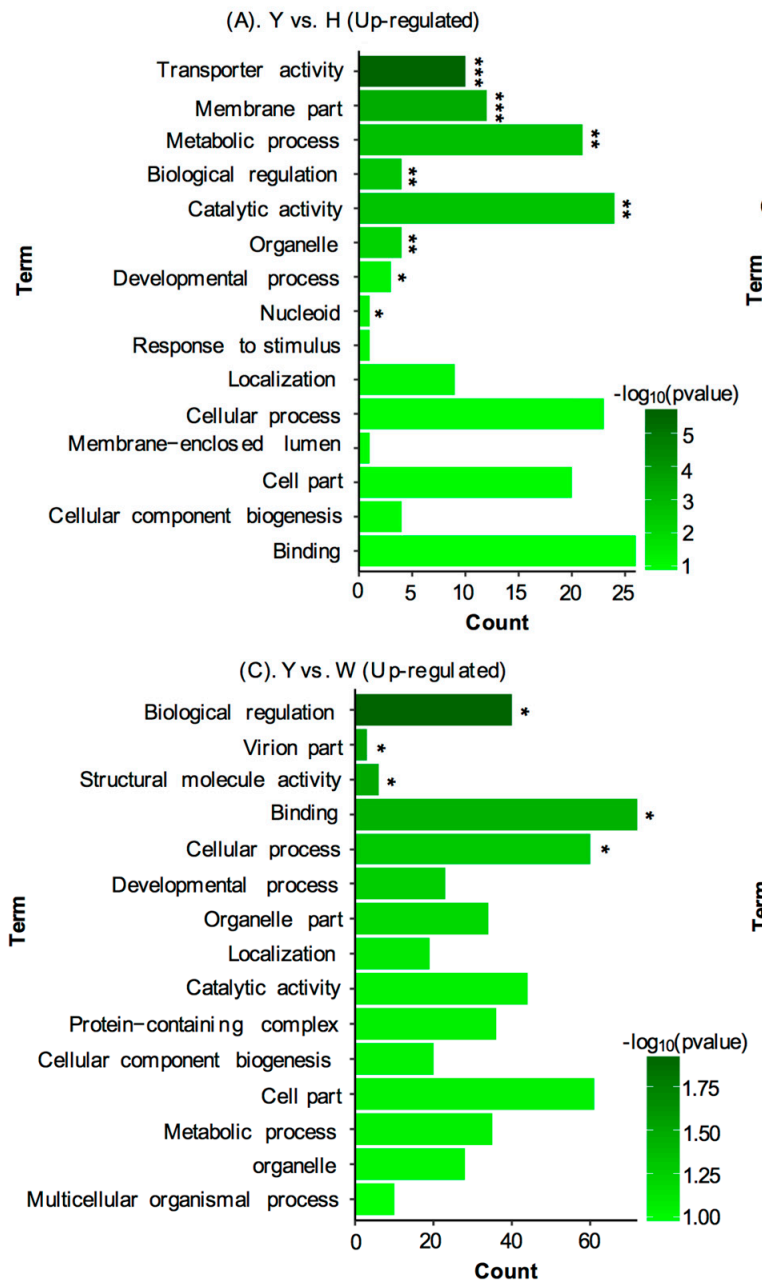
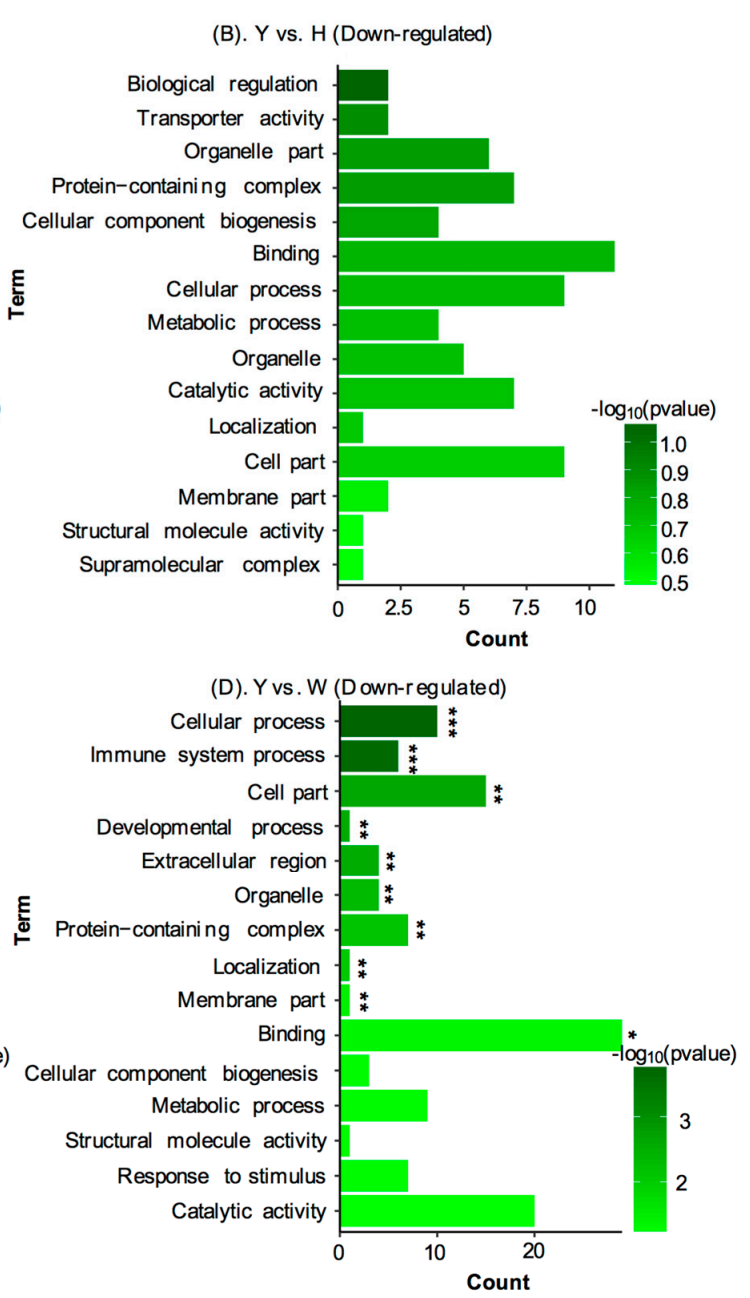

Figure 5. Gene ontology (GO) enrichment analysis of DEPs among $\mathrm{Y}, \mathrm{B}$, and W. Statistics of top 15 enriched GO terms for DEPs in yellow skin (A) and black skin (B) in Jinbian carp; Statistics of top 15 enriched GO terms for DEPs in Y (C) and W (D); $p<0.001$ is marked as "****", $p<0.01$ is marked as “***, and $p<0.05$ is marked as "**". 

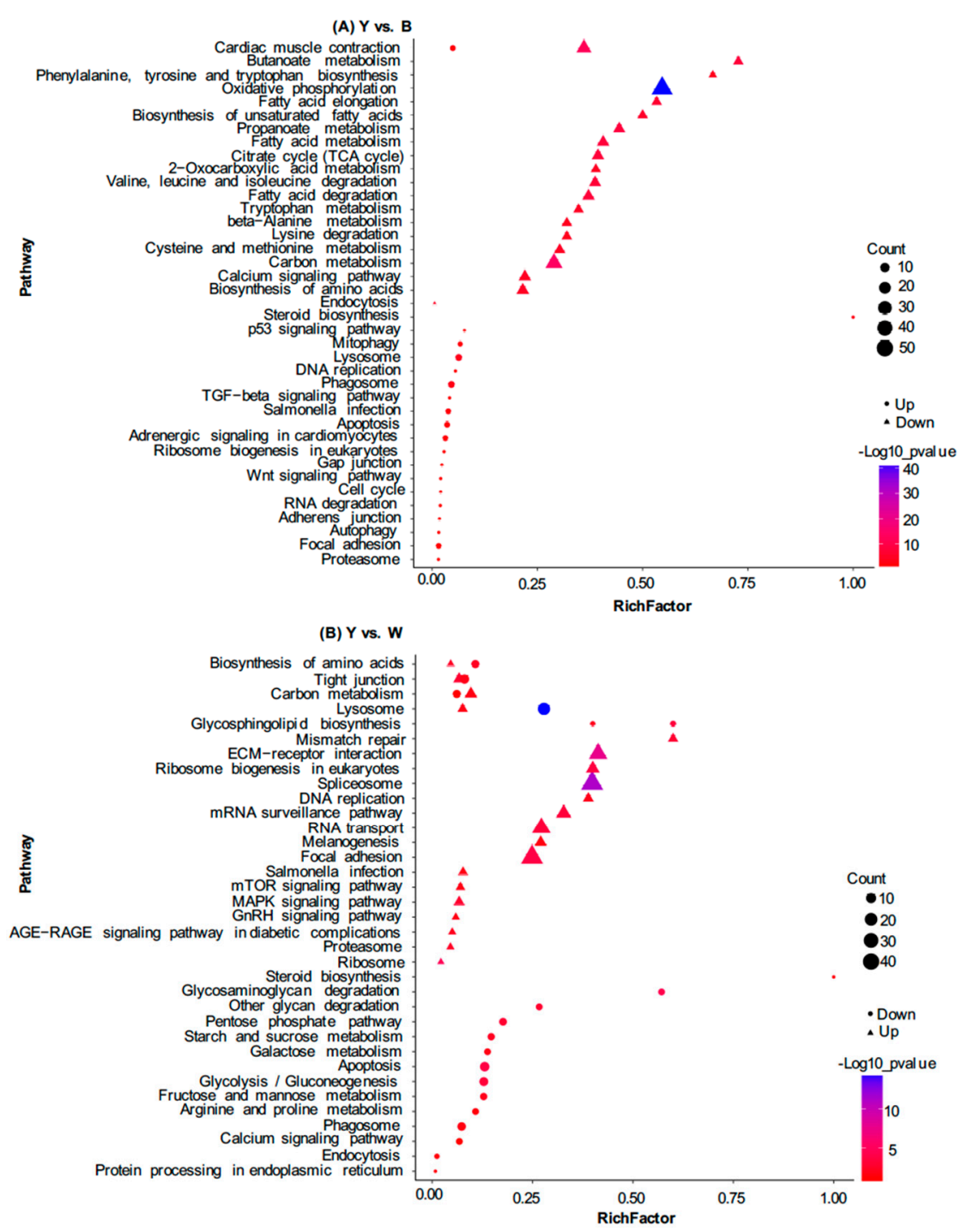

Figure 6. Kyoto Encyclopedia of Genes and Genomes (KEGG) pathway enrichment analysis for DEPs in Y, B, and W. Statistics of top 20 enriched pathways for DEPs in Y and B (A); Statistics of top 20 enriched pathways for DEPs in $\mathrm{Y}$ and $\mathrm{W}(\mathbf{B})$. The abscissa represents the enrichment factor.

\subsection{DEP Analysis between Yellow Skin in Jinbian Carp (Y) and Black Skin in Wild Common Carp (W)}

A total of 129 DEPs were also identified between $\mathrm{Y}$ and $\mathrm{W}$ (FC $\geq 1.2$ and $p$-value $<0.05$ (Figure 4B), among which included 58 up-regulated proteins (Table 3 ) and 71 down-regulated proteins in Y (Table 4). GO analysis showed that most up-regulated genes in $\mathrm{Y}$ were grouped into biological regulation, virion part, structural molecule activity, binding, cellular process, developmental process, organelle part, localization, catalytic activity, protein-containing complex, cellular component biogenesis, cell part, metabolic process, organelle, and multicellular organismal process (Figure 5C). In addition, most down-regulated DEPs in $\mathrm{Y}$ compared to $\mathrm{W}$ were grouped into cellular process, immune system process, cell part, developmental process, extracellular region, organelle, protein-containing complex, localization, membrane part, and binding (Figure 5D).

KEGG analysis showed that up-regulated genes in $\mathrm{Y}$ compared to $\mathrm{W}$ were preferentially grouped into lysosome (22/84), apoptosis (11/84), tight junction (10), glycolysis/gluconeogenesis (nine), phagosome (eight), biosynthesis of amino acids (seven), carbon metabolism (seven), pentose phosphate pathway (six), focal adhesion (five), regulation of actin cytoskeleton (five), starch and sucrose metabolism (five), fructose and mannose metabolism (five), salmonella infection (four), galactose metabolism (four), glycosaminoglycan degradation (four), adrenergic signaling in cardiomyocytes 
(four), calcium signaling pathway (four), cardiac muscle contraction (four), arginine and proline metabolism (four), and MAPK signaling pathway (three) (Figure 6B). In addition, the down-regulated genes in $Y$ compared to $W$ were mainly grouped into spliceosome (49/354), focal adhesion (48), RNA transport (31), ECM-receptor interaction (31), regulation of actin cytoskeleton (24), endocytosis (22), mRNA surveillance pathway (19), protein processing in endoplasmic (17), reticulum (15), phagsome (14), ribosome biogenesis in eukaryotes (14), insulin signaling pathway (14), apoptosis (13), necroptoiss (12), adrenergic signaling in cardiomyocytes (11), carbon metabolism (11), melanogenesis (10), and apelin signaling pathway (10) (Figure 6B).

Table 3. The DEPs up-regulated in $\mathrm{W}$ compared to $\mathrm{Y}(\mathrm{FC} \geq 1.6)$.

\begin{tabular}{|c|c|c|c|c|}
\hline Uniprot_ID & Gene & Description & $\mathrm{FC}(\mathrm{W} / \mathrm{Y})$ & $p$ Value \\
\hline HIBCH_DANRE & hibch & 3-hydroxyisobutyryl-CoA hydrolase & 4.52 & 0.0106552 \\
\hline RD23A_MOUSE & $\operatorname{Rad} 23 a$ & $\begin{array}{c}\text { UV excision repair protein RAD23 } \\
\text { homolog A }\end{array}$ & 3.47 & 0.0130752 \\
\hline MREG_DANRE & mreg & Melanoregulin & 3.20 & $3.6735 \times 10^{-5}$ \\
\hline LAMB1_HUMAN & $L A M B 1$ & Laminin subunit beta-1 & 3.18 & 0.0192734 \\
\hline FBXL7_MOUSE & Fbxl7 & F-box/LRR-repeat protein 7 & 2.48 & 0.0064965 \\
\hline MX2_ONCMY & $m \times 2$ & $\begin{array}{l}\text { Interferon-induced GTP-binding } \\
\text { protein } \mathrm{M} \times 2 \\
\end{array}$ & 2.43 & 0.0299254 \\
\hline K1C1_CARAU & $N / A$ & Keratin & 2.36 & 0.0008656 \\
\hline ST2B1_MOUSE & Sult $2 b 1$ & $\begin{array}{l}\text { Sulfotransferase family cytosolic } 2 \mathrm{~B} \\
\text { member } 1\end{array}$ & 2.27 & 0.0020935 \\
\hline TBCB_BOVIN & $T B C B$ & Tubulin-folding cofactor B & 2.26 & 0.0141326 \\
\hline CMYA5_HUMAN & CMYA5 & Cardiomyopathy-associated protein 5 & 2.17 & 0.0476189 \\
\hline NFL_COTJA & NEFL & Neurofilament light polypeptide & 2.14 & 0.0275144 \\
\hline ETFA_HUMAN & ETFA & $\begin{array}{l}\text { Electron transfer flavoprotein subunit } \\
\text { alpha }\end{array}$ & 1.97 & 0.0429857 \\
\hline MYPC3_CHICK & MYBPC3 & Myosin-binding protein C & 1.92 & 0.0243995 \\
\hline RDH12_HUMAN & RDH12 & Retinol dehydrogenase 12 & 1.92 & 0.0340642 \\
\hline CWC22_DANRE & $c w c 22$ & $\begin{array}{c}\text { Pre-mRNA-splicing factor CWC22 } \\
\text { homolog }\end{array}$ & 1.89 & 0.0230742 \\
\hline AT2A1_MAKNI & atp $2 a 1$ & $\begin{array}{c}\text { Sarcoplasmic/endoplasmic reticulum } \\
\text { calcium ATPase } 1\end{array}$ & 1.85 & 0.0471695 \\
\hline PLEC_MOUSE & Plec & Plectin & 1.84 & 0.0021985 \\
\hline GSE1_DANRE & gse1 & Genetic suppressor element 1 & 1.83 & 0.0457959 \\
\hline PLEC_HUMAN & PLEC & Plectin & 1.81 & 0.0268665 \\
\hline OPA1_DANRE & opa1 & Dynamin-like 120 kDa protein & 1.81 & 0.0430209 \\
\hline LAMA4_HUMAN & $L A M A 4$ & Laminin subunit alpha- 4 & 1.81 & 0.0229941 \\
\hline DCXR_MESAU & $D C X R$ & L-xylulose reductase & 1.81 & 0.0028180 \\
\hline A2MP_MOUSE & $A 2 m$ & Alpha-2-macroglobulin-P & 1.80 & 0.0145305 \\
\hline MF2NB_DANRE & borcs8 & Protein MEF2BNB & 1.80 & 0.0487061 \\
\hline SYK_HUMAN & KARS & Lysine-tRNA ligase & 1.80 & 0.0010683 \\
\hline SPAG7_DANRE & spag7 & Sperm-associated antigen 7 homolog & 1.76 & 0.0268045 \\
\hline COX42_THUOB & $N / A$ & $\begin{array}{l}\text { Cytochrome c oxidase subunit } 4 \\
\text { isoform } 2\end{array}$ & 1.76 & 0.0198968 \\
\hline
\end{tabular}


Table 3. Cont.

\begin{tabular}{|c|c|c|c|c|}
\hline Uniprot_ID & Gene & Description & $\mathrm{FC}(\mathrm{W} / \mathrm{Y})$ & $p$ Value \\
\hline AT2A1_RABIT & $A T P 2 A 1$ & $\begin{array}{c}\text { Sarcoplasmic/endoplasmic reticulum } \\
\text { calcium ATPase } 1\end{array}$ & 1.75 & 0.0471735 \\
\hline NUP98_RAT & Nup98 & $\begin{array}{l}\text { Nuclear pore complex protein } \\
\text { Nup98-Nup96 }\end{array}$ & 1.75 & 0.0376341 \\
\hline ALKB5_DANRE & alkbh5 & RNA demethylase ALKBH5 & 1.73 & 0.0135027 \\
\hline CLIC2_HUMAN & CLIC2 & Chloride intracellular channel protein 2 & 1.72 & 0.0347927 \\
\hline TYRP1_CARAU & tyrp1 & $\begin{array}{c}\text { 5,6-dihydroxyindole-2-carboxylic acid } \\
\text { oxidase } 5\end{array}$ & 1.72 & 0.0002676 \\
\hline RRBP1_HUMAN & $R R B P 1$ & Ribosome-binding protein 1 & 1.71 & 0.0366481 \\
\hline SRSF5_HUMAN & SRSF5 & Serine/arginine-rich splicing factor 5 & 1.70 & 0.0002839 \\
\hline COCA1_CHICK & COL12A1 & Collagen alpha-1(XII) chain & 1.70 & 0.0262727 \\
\hline AGRB2_MOUSE & Adgrb2 & $\begin{array}{l}\text { Adhesion G protein-coupled receptor } \\
\text { B2 }\end{array}$ & 1.70 & 0.0044674 \\
\hline LPIN1_HUMAN & LPIN1 & Phosphatidate phosphatase LPIN1 & 1.69 & 0.0197062 \\
\hline PLIN5_RAT & Plin5 & Perilipin-5 & 1.69 & 0.0165470 \\
\hline CALD1_MELGA & CALD1 & Caldesmon & 1.67 & 0.0016593 \\
\hline PMEL_CHICK & PMEL & Melanocyte protein PMEL & 1.67 & 0.0316520 \\
\hline RM43_BOVIN & MRPL43 & $39 S$ ribosomal protein L43 & 1.67 & 0.0311367 \\
\hline AIP_RAT & Aip & AH receptor-interacting protein & 1.66 & 0.0455057 \\
\hline MRP_BOVIN & MARCKSL1 & MARCKS-related protein & 1.65 & 0.0044254 \\
\hline PSMF1_PONAB & PSMF1 & Proteasome inhibitor PI31 subunit & 1.65 & 0.0351891 \\
\hline PTX3_HUMAN & PTX3 & Pentraxin-related protein PTX3 & 1.64 & 0.0357322 \\
\hline HSP7E_DANRE & hspa14 & Heat shock $70 \mathrm{kDa}$ protein 14 & 1.64 & 0.0100857 \\
\hline K2C8_HUMAN & KRT8 & Keratin & 1.64 & 0.0073882 \\
\hline TPD54_HUMAN & TPD52L2 & Tumor protein D54 & 1.63 & 0.0281041 \\
\hline PGS2_BOVIN & $D C N$ & Decorin & 1.63 & 0.0046897 \\
\hline TRI11_RAT & Trim11 & E3 ubiquitin-protein ligase TRIM11 & 1.63 & 0.0092775 \\
\hline RPF2_BOVIN & $R P F 2$ & Ribosome production factor 2 homolog & 1.63 & 0.0380427 \\
\hline ECHD1_DANRE & echdc1 & Ethylmalonyl-CoA decarboxylase & 1.63 & 0.0064541 \\
\hline SNAB_HUMAN & $N A P B$ & Beta-soluble NSF attachment protein & 1.62 & 0.0255251 \\
\hline PKP3_MOUSE & Pkp3 & Plakophilin-3 & 1.61 & 0.0044704 \\
\hline SSF1_MOUSE & Ppan & Suppressor of SWI4 1 homolog & 1.61 & 0.0288496 \\
\hline ADDG_HUMAN & ADD3 & Gamma-adducin & 1.61 & 0.0010349 \\
\hline PBX1_HUMAN & PBX1 & $\begin{array}{l}\text { Pre-B-cell leukemia transcription factor } \\
1\end{array}$ & 1.60 & 0.0001923 \\
\hline RTN1_PANTR & RTN1 & Reticulon-1 & 1.60 & 0.0389269 \\
\hline
\end{tabular}


Table 4. The DEPs up-regulated in $\mathrm{Y}$ compared to $\mathrm{W}(\mathrm{FC} \geq 1.5)$.

\begin{tabular}{|c|c|c|c|c|}
\hline Uniprot_ID & Gene & Description & $\mathrm{FC}(\mathrm{Y} / \mathrm{W})$ & $p$ Value $(\mathrm{W} / \mathrm{Y})$ \\
\hline MYOM2_HUMAN & MYOM2 & Myomesin-2 & 4.87 & 0.0034066 \\
\hline DDR2_MOUSE & $D d r 2$ & $\begin{array}{l}\text { Discoidin domain-containing } \\
\text { receptor } 2\end{array}$ & 4.68 & 0.0283762 \\
\hline TNNC2_ANGAN & $N / A$ & Troponin C & 4.50 & 0.0072123 \\
\hline MYOZ1_HUMAN & MYOZ1 & Myozenin-1 & 4.01 & 0.0065529 \\
\hline MYSS_CYPCA & $N / A$ & Myosin heavy chain & 3.53 & 0.0017226 \\
\hline PRV2_DANRE & pvalb2 & Parvalbumin-2 & 3.34 & 0.0176125 \\
\hline MYOZ1_BOVIN & MYOZ1 & Myozenin-1 & 3.25 & 0.0011707 \\
\hline ACTN3_BOVIN & ACTN3 & Alpha-actinin-3 & 3.09 & 0.0014259 \\
\hline PDLI7_BOVIN & PDLIM7 & PDZ and LIM domain protein 7 & 3.05 & 0.0062208 \\
\hline SAHHB_XENLA & $a h c y-b$ & Adenosylhomocysteinase B & 3.01 & 0.0097743 \\
\hline TITIN_HUMAN & TTN & Titin & 2.97 & 0.0040666 \\
\hline DYST_HUMAN & DST & Dystonin & 2.90 & 0.0213198 \\
\hline MYBPH_CHICK & MYBPH & Myosin-binding protein $\mathrm{H}$ & 2.83 & 0.0015750 \\
\hline CASR_BOVIN & CASR & $\begin{array}{l}\text { Extracellular calcium-sensing } \\
\text { receptor }\end{array}$ & 2.81 & 0.0064296 \\
\hline NRG_DROME & $\mathrm{Nrg}$ & Neuroglian & 2.75 & 0.0083956 \\
\hline MTUS2_HUMAN & MTUS2 & $\begin{array}{l}\text { Microtubule-associated tumor } \\
\text { suppressor candidate } 2\end{array}$ & 2.74 & 0.0214764 \\
\hline MYPC2_MOUSE & Mybpc2 & Myosin-binding protein $C$ & 2.72 & 0.0059417 \\
\hline AMPD1_HUMAN & AMPD1 & AMP deaminase 1 & 2.61 & 0.0074214 \\
\hline MAP7_CHICK & MAP7 & Ensconsin & 2.61 & 0.0064867 \\
\hline TNNT3_COTJA & TNNT3 & Troponin $\mathrm{T}$ & 2.60 & $8.4696 \times 10^{-5}$ \\
\hline GIMA5_HUMAN & GIMAP5 & GTPase IMAP family member 5 & 2.29 & 0.0243491 \\
\hline AOXC_MOUSE & Aox3 & Aldehyde oxidase 3 & 2.22 & 0.0150366 \\
\hline K1C14_MOUSE & Krt14 & Keratin & 2.17 & 0.0462584 \\
\hline TNNI2_RABIT & TNNI2 & Troponin I & 2.16 & 0.0005866 \\
\hline KPYM_CHICK & PKM & Pyruvate kinase PKM & 2.16 & 0.0370822 \\
\hline MPSF_CHICK & $N / A$ & M-protein & 2.13 & 0.0065892 \\
\hline KCRM_CANFA & CKM & Creatine kinase M-type & 2.11 & 0.0154615 \\
\hline LDB3_HUMAN & $L D B 3$ & LIM domain-binding protein 3 & 2.10 & 0.0389130 \\
\hline FUCO_HUMAN & FUCA1 & Tissue alpha-L-fucosidase & 2.06 & 0.0105965 \\
\hline MYO1F_HUMAN & MYO1F & Unconventional myosin-If & 2.04 & 0.0272882 \\
\hline KPCD_HUMAN & PRKCD & Protein kinase $C$ delta type & 2.01 & 0.0146456 \\
\hline FLNC_RAT & $F \ln c$ & Filamin-C & 2.01 & 0.0345344 \\
\hline TPM3_HUMAN & TPM3 & Tropomyosin alpha-3 chain & 1.99 & 0.0062754 \\
\hline RNT2_DANRE & rnaset2 & Ribonuclease T2 & 1.99 & 0.0007026 \\
\hline CHP3_XENLA & tesc & Calcineurin B homologous protein 3 & 1.98 & 0.0098880 \\
\hline VTNC_RABIT & VTN & Vitronectin & 1.97 & 0.0419940 \\
\hline ACTSA_TAKRU & acta1a & Actin & 1.94 & 0.0035608 \\
\hline FUCO_MOUSE & Fucal & Tissue alpha-L-fucosidase & 1.91 & 0.0197286 \\
\hline
\end{tabular}


Table 4. Cont.

\begin{tabular}{|c|c|c|c|c|}
\hline Uniprot_ID & Gene & Description & $\mathrm{FC}(\mathrm{Y} / \mathrm{W})$ & $p$ Value $(\mathrm{W} / \mathrm{Y})$ \\
\hline MYH4_HUMAN & MYH4 & Myosin- 4 & 1.86 & 0.0243060 \\
\hline IF44L_MOUSE & Ifi44l & Interferon-induced protein 44-like & 1.86 & 0.0264745 \\
\hline BAX_BOVIN & $B A X$ & Apoptosis regulator BAX & 1.84 & 0.0027166 \\
\hline NEBU_HUMAN & $N E B$ & Nebulin & 1.84 & 0.0041143 \\
\hline AKA12_HUMAN & AKAP12 & A-kinase anchor protein 12 & 1.82 & 0.0224758 \\
\hline EF1A1_HORSE & EEF1A1 & Elongation factor 1-alpha 1 & 1.81 & 0.0125514 \\
\hline K1C13_ONCMY & $k r t 13$ & Keratin & 1.80 & 0.0162506 \\
\hline FUCM_DANRE & fuom & Fucose mutarotase & 1.77 & 0.0014529 \\
\hline TIMP3_XENLA & timp3 & Metalloproteinase inhibitor 3 & 1.74 & 0.0209090 \\
\hline CNIH4_BOVIN & $\mathrm{CNIH} 4$ & Protein cornichon homolog 4 & 1.72 & 0.0420714 \\
\hline PDLI7_MOUSE & Pdlim7 & PDZ and LIM domain protein 7 & 1.70 & 0.0173236 \\
\hline CATB_CHICK & CTSB & Cathepsin B & 1.69 & 0.0004048 \\
\hline OBSCN_MOUSE & Obscn & Obscurin & 1.68 & 0.0015550 \\
\hline MYOZ2_PONAB & MYOZ2 & Myozenin-2 & 1.66 & 0.0485948 \\
\hline SAP_CHICK & PSAP & Prosaposin & 1.66 & 0.0389310 \\
\hline PUA1A_SALSA & adssl1a & $\begin{array}{c}\text { Adenylosuccinate synthetase } \\
\text { isozyme } 1 \mathrm{~A}\end{array}$ & 1.65 & 0.0115606 \\
\hline CFAB_BOVIN & $C F B$ & Complement factor B & 1.64 & 0.0096244 \\
\hline LEG12_HUMAN & LGALS12 & Galectin-12 & 1.63 & 0.0231777 \\
\hline WDR47_MOUSE & $W d r 47$ & WD repeat-containing protein 47 & 1.62 & 0.0030872 \\
\hline ALDOA_MOUSE & Aldoa & Fructose-bisphosphate aldolase A & 1.62 & 0.0033610 \\
\hline CFAB_MOUSE & $C f b$ & Complement factor B & 1.60 & 0.0027860 \\
\hline G3P_CHICK & GAPDH & $\begin{array}{c}\text { Glyceraldehyde-3-phosphate } \\
\text { dehydrogenase }\end{array}$ & 1.58 & 0.0436886 \\
\hline DMD_CHICK & $D M D$ & Dystrophin & 1.56 & 0.0007040 \\
\hline PPGB_MOUSE & Ctsa & Lysosomal protective protein & 1.55 & 0.0207043 \\
\hline DPP2_MOUSE & $D p p 7$ & Dipeptidyl peptidase 2 & 1.54 & 0.0001501 \\
\hline TITIN_MOUSE & Ttn & Titin & 1.54 & 0.0002004 \\
\hline NUPR2_HUMAN & NUPR2 & Nuclear protein 2 & 1.53 & 0.0135287 \\
\hline LGMN_BOVIN & $L G M N$ & Legumain & 1.53 & 0.0159403 \\
\hline BGLR_MOUSE & Gusb & Beta-glucuronidase & 1.53 & 0.0195223 \\
\hline CATH_PIG & $\mathrm{CTSH}$ & Pro-cathepsin $\mathrm{H}$ & 1.52 & 0.0364061 \\
\hline ING5_HUMAN & ING5 & Inhibitor of growth protein 5 & 1.52 & 0.0011046 \\
\hline ALDOA_SALSA & $N / A$ & Fructose-bisphosphate aldolase A & 1.51 & 0.0039936 \\
\hline CAPZB_CHICK & $C A P Z B$ & $\begin{array}{l}\text { F-actin-capping protein subunit } \\
\text { beta isoforms } 1 \text { and } 2\end{array}$ & 1.51 & 0.0220029 \\
\hline
\end{tabular}

\section{Discussion}

The common carp has been widely farmed in Europe and Asia. In the long-term breeding process, the common carp has evolved hundreds of strains or varieties that display a rich biodiversity and are 
diverse in skin colors [13]. Due to their diverse skin colors, the common carp was used as a good model to elucidate the skin pigmentation process. Various fish colorations are determined by the density and position of different pigment cells, which is believed to be mainly controlled by genetic factors. As we know, both the melanin and the pteridine synthesis pathways have been found in teleost. The black pigment, melanin, is generated in melanophores through the melanin synthesis pathway [2], and the pteridine synthesis pathway could produce the yellow or reddish pteridine pigments [14]. Now, several genes have been identified in black and yellow pigment synthesis [2], but the detail molecular mechanisms of different pigment synthesis were not well understood. In the present study, to better understand fish skin color genetics, iTRAQ was used to examine the differentially expressed proteins between the melanin synthesis pathway and pteridine synthesis pathway in common carp.

\subsection{Skin Proteome Analysis}

As a first step, 8064 protein kits were detected in common carp skin. GO analysis showed that most proteins were enriched in the immune system process, including endocytosis, phagosome, necroptosis, lysosome, and salmonella infection. These results confirmed that the major function of fish skin is to act as the first barrier of the immune system. It can provide protection against physical damage and assisted with the maintenance of homoeostasis by minimizing exchange between the animal and the environment. The goblet cells in the skin epidermis are responsible for the production of the mucosal layer [15]. The skin mucus is a composite of defensive molecules, including antibodies, together with factors of both the innate and acquired immune system [16]. The mucins are the major macromolecular components of mucus [17]. Mucins are heavily glycosylated proteins, which impart viscoelastic and rheological properties to mucosal layers [18]. In addition, we also found that many proteins are grouped into transporter activity, binding, and membrane-enclosed lumen in common carp skin proteomes. These results indicate that the skin in common carp also plays an important role in transporting gases, ions, nitrogenous waste products, and nutrients [19].

\subsection{Up-Regulated Proteins in Black Skin Indicated the Molecular Mechanism of the Melanin Synthesis Pathway}

Melanin is mainly synthesized by tyrosine within the melanosome [20,21]. In mammals and birds, two types of melanin are produced, the black or brown eumelanin and the lighter pheomelanin, but only eumelanin has been observed in teleost [22]. Eumelanin is synthesized by tyrosine within the melanosome of melanophores. This requires members of the tyrosinase family (TYP, DCT, and TYRPI) and probably Silver (SILV) [23-26]. Three melanosomal transporters (OCA2, AIMI, and SLC24A5) are crucial for proper melanin synthesis [27]. In the present study, we also found that several up-regulated proteins (Rad23a, mreg, tyrp1, and PMEL) in black skin were grouped into the melanogenesis pathway, including melanoregulin, melanocyte protein, and the UV excision repair protein, which might be responsible for the melanogenesis in the black skin of Jinbian carp. Given that the zebrafish golded mutant caused by slc24a 5 deficiency is characterized by delayed and reduced development of melanin pigmentation, the up-regulated SLC25A4, SLC25A5, and SLC25A6 in the black skin may also associate with skin color variation $[27,28]$. However, we did not detect the different expression of TYP, DCT, and SILV between yellow and black skin, which indicated that these proteins might also play a role in the synthesis of yellow pigment. In addition, consistent with our recent transcriptome analysis, we also discovered that ACTC1, MYH6, and MYH7, involved in adrenergic signaling pathway, and ATP2A1, ATP2A2, ATP5F1, ATP5J, and COX5A, involved in oxidative metabolism pathway, were also up-regulated in black skin compared to yellow skin in proteome analysis [29]. Consequently, these genes could be candidate genes for the formation of yellow or black colors in Jinbian carp. 


\subsection{Up-Regulated Proteins in Yellow Skin Indicated the Molecular Mechanism of the Pteridine Synthesis Pathways}

The yellow and reddish pteridine pigments are synthesized from GTP through the pteridine synthesis pathway in xanthophores. Three component pathways are involved in pteridine synthesis. Firstly, the GTP are converted into the tetrahydrobiopterin (H4biopterin), which is a cofactor for neurotransmitter synthesis and tyrosinase activity in melanophores. The second component is the regeneration pathway of oxidized H4biopterin. The third pathway shares several steps with the first one and leads to the formation of the yellow pigments, sepiapterin, and its derivatives $[2,14]$. During these processes, several genes were involved in the yellow pigmentation, such as the GTP cyclohydrolase I (GchI) [14], 6-pyruvoyltetrahydropterin synthase (Pts), sepiapterin reductase (Spr), xanthine oxidase/xanthine dehydrogenase $(\mathrm{Xod} / \mathrm{Xdh})$, and protein associated with Myc (PAM) [30]. In the present study, KEGG analysis showed that up-regulated proteins in yellow skin were preferentially grouped into several metabolism process, such as arginine and proline metabolism, pentose phosphate pathway, glycolysis/gluconeogenesis, fructose and mannose metabolism, carbon metabolism, and galactose metabolism. In addition, a few of the up-regulated proteins in yellow skin were also found to be related to nucleotide metabolism, such as GTPase IMAP family member 5 (GIMAP5), AMP deaminase 1 (AMPD1), adenosylhomocysteinase $b$ (ahcy-b), and pyruvate kinase (PKM). These proteins may also play an important role in the yellow pigmentation.

In summary, we conducted a proteomic analysis among the yellow and black skin of Jinbian carp and the black skin of the wild common carp by using iTRAQ technology, and the results indicated that several up-regulated DEPs in black skin, including Rad23a, mreg, tyrp1, and PMEL, and several up-regulated DEPs in yellow skin, including GIMAP5, AMPD1, ahcy-b, and PKM, might be involved in the color variation in Jinbian carp.

Supplementary Materials: The following are available online at http://www.mdpi.com/2075-1729/10/10/226/s1, Table S1: Raw data analysis of the proteomic data among yellow skin in Jinbian carp (Y), black skin in Jinbian carp (B), and black skin in wild common carp (W).

Author Contributions: Data curation: X.Y. (Xiangchen Ye), L.Z. and J.J.; Resources: L.W., Y.W. and J.H.; Software: L.Z., J.J. and X.Y. (Xueyu Yan); Methodology: B.G. and K.L.; Funding acquisition: X.Y. (Xiangchen Ye) and Y.L.; Project administration: G.H. and X.Y. (Xiangchen Ye); Writing—original draft: J.J. and G.H.; Writing-review and editing: L.Z. and G.H. All authors have read and agreed to the published version of the manuscript.

Funding: Financial support was provided from China Postdoctoral Science Foundation (237934 to G.F.), Fundamental Research Funds for the Central Universities (2662019PY006 to G.F.), and China Agriculture Research System (CARS-45).

Acknowledgments: This article is dedicated to Zhong Li (Yangtze River Fisheries Institute) for his genuine interest in training young scientists in the field of fish breeding.

Conflicts of Interest: The authors declare no conflict of interest.

\section{References}

1. Hubbard, J.K.; Uy, J.A.; Hauber, M.E.; Hoekstra, H.E.; Safran, R.J. Vertebrate pigmentation: From underlying genes to adaptive function. Trends Genet. 2010, 26, 231-239. [CrossRef] [PubMed]

2. Braasch, I.; Schartl, M.; Volff, J.N. Evolution of pigment synthesis pathways by gene and genome duplication in fish. BMC Evol. Biol. 2007, 7, 74. [CrossRef] [PubMed]

3. Parichy, D.M. Pigment patterns: Fish in stripes and spots. Curr. Biol. 2003, 13, 947-950. [CrossRef] [PubMed]

4. Guo, H.; Huang, B.; Qi, F.; Zhang, S. Distribution and ultrastructure of pigment cells in the skins of normal and albino adult turbot, Scophthalmus maximus. Chin. J. Oceanol. Limnol. 2007, 25, 199-208. [CrossRef]

5. Zarnescu, O. Ultrastructure of the skin melanophores and iridophores in paddlefish, Polyodon spathula. Micron 2007, 38, 81-84. [CrossRef]

6. Failde, L.D.; Bermudez, R.; Vigliano, F.; Coscelli, G.A.; Quiroga, M.I. Morphological, immunohistochemical and ultrastructural characterization of the skin of turbot (Psetta maxima L.). Tissue Cell 2014, 46, 334-342. [CrossRef] 
7. Haffter, P.; Odenthal, J.; Mullins, M.C.; Lin, S.; Farrell, M.J.; Vogelsang, E.; Haas, F.; Brand, M.; van Eeden, F.J.; Furutani-Seiki, M.; et al. Mutations affecting pigmentation and shape of the adult zebrafish. Dev. Genes Evol. 1996, 206, 260-276. [CrossRef]

8. Wohlfarth, G.W. Common carp. In Evolution of Domesticated Animals; Mason, J.L., Ed.; Longman: London, UK; New York, NY, USA, 1984; pp. 375-380.

9. Balon, E.K. The common carp, Cyrpinus carpio: Its wild origin, domestication in aquaculture, and selection as colored nishigoi. Guelph Ichthyol. Rev. 1995, 3, 1-54.

10. Hulata, G. A review of genetic improvement of the common carp (Cyprinus carpio L.) and other cyprinids by crossbreeding, hybridization and selection. Aquaculture 1995, 129, 143-155. [CrossRef]

11. Ye, X.; Lv, Y.J.; Wei, L.J.; Huang, J.; Wen, Y.H.; Zhang, G.J.; Zhang, S.; Yang, Z.S.; Liu, K. The complete mitochondrial genome of Jinbian carp Cyprinus carpio (Cypriniformes: Cyprinidae). Mitochondrial DNA Part B 2018, 3, 1096-1097. [CrossRef]

12. Jia, J.Y.; Liu, X.J.; Li, L.; Lei, C.Q.; Dong, Y.; Wu, G.Q. Transcriptional and translational relationship in environmental stress: RNAseq and ITRAQ proteomic analysis between sexually reproducing and parthenogenetic females in Monia micrura. Front. Physiol. 2018, 9, 812. [CrossRef] [PubMed]

13. Jiang, Y.L.; Zhang, S.H.; Xu, J.; Feng, J.X.; Mahboob, S.; AI-Ghanim, K.A.; Sun, X.W.; Xu, P. Comparative transcriptome analysis reveals the genetic basis of skin color variation in common carp. PLoS ONE 2014, 9, e108200. [CrossRef] [PubMed]

14. Ziegler, I. The pteridine pathway in zebrafish: Regulation and specification during the determination of neural crest cell-fate. Pigment Cell Res. 2003, 16, 172-182. [CrossRef] [PubMed]

15. Harris, J.E.; Hunt, S. The fine structure of the epidermis of two species of salmonid fish, the Atlantic salmon (Salmo salar L.) and the brown trout (Salmo trutta L.): II. mucous cells. Cell Tissue Res. 1975, 163, 535-543. [CrossRef]

16. Perez-Sanchez, J.; Terova, G.; Simo-Mirabet, P.; Rimoldi, S.; folkedal, O.; Calduch-Giner, J.A.; Olsen, R.E.; Sitja-Bobadilla, A. Skin mucus of gilthead sea bream (Sparus aurata L.). Protein mapping and regulation in chronically stressed fish. Front. Physiol. 2017, 8, 34. [CrossRef]

17. Phillipson, M.; Johansson, M.E.; Henriksnas, J.; Petersson, J.; Gendler, S.J.; Sandler, S.; Persson, A.E.; Hansson, G.C.; Holm, L. The gastric mucus layers: Constituents and regulation of accumulation. Am. J Physiol. Gastrointest. Liver Physiol. 2008, 29, G806-G812. [CrossRef]

18. Thornton, D.J.; Rousseau, K.; McGuckin, M.A. Structure and function of the polymeric mucins in airways mucus. Annu. Rev. Physiol. 2008, 70, 459-486. [CrossRef]

19. Glover, C.N.; Bucking, C.; Wood, C.M. The skin of fish as a transport epithelium: A review. J. Comp. Physiol. B 2013, 183, 877-891. [CrossRef]

20. Hearing, V.J.; Tsukamoto, K. Enzymatic control of pigmentation in mammals. FASEB J. 1991, 5, $2902-2909$. [CrossRef]

21. del Marmol, V.; Beermann, F. Tyrosinase and related proteins in mammalian pigmentation. FEBS Lett. 1996, 381, 165-168. [CrossRef]

22. Fujii, R. Coloration and chromatophores. In The Physiology of Fishes; Evans, D.H., Ed.; CRC Press: Boca Raton, FL, USA, 1993; pp. 535-562.

23. Fukamachi, S.; Asakawa, S.; Wakamatsu, Y.; Shimizu, N.; Mitani, H.; Shima, A. Conserved function of medaka pink-eyed dilution in melanin synthesis and its divergent transcriptional regulation in gonads among vertebrates. Genetics 2004, 168, 1519-1527. [CrossRef] [PubMed]

24. Fukamachi, S.; Shimada, A.; Shima, A. Mutations in the gene encoding B, a novel transporter protein, reduce melanin content in medaka. Nat. Genet. 2001, 28, 381-385. [CrossRef] [PubMed]

25. Protas, M.E.; Hersey, C.; Kochanek, D.; Zhou, Y.; Wilkens, H.; Jeffery, W.R.; Zon, L.I.; Borowsky, R.; Tabin, C.J. Genetic analysis of cavefish reveals molecular convergence in the evolution of albinism. Nat. Genet. 2006, 38, 107-111. [CrossRef] [PubMed]

26. Schonthaler, H.B.; Lampert, J.M.; von Lintig, J.; Schwarz, H.; Geisler, R.; Neuhauss, S.C. A mutation in the silver gene leads to defects in melanosome biogenesis and alterations in the visual system in the zebrafish mutant fading vision. Dev. Biol. 2005, 284, 421-436. [CrossRef]

27. Lamason, R.L.; Mohideen, M.A.; Mest, J.R.; Wong, A.C.; Norton, H.L.; Aros, M.C.; Jurynec, M.J.; Mao, X.; Humphreville, V.R.; Humbert, J.E.; et al. SLC24A5, a putative cation exchanger, affects pigmentation in zebrafish and humans. Science 2005, 310, 1782-1786. [CrossRef] 
28. Dooley, C.M.; Schwarz, H.; Mueller, K.P.; Mongera, A.; Konantz, M.; Neuhauss, S.C.F.; Nüsslein-Volhard, C.; Geisler, R. Slc45a2 and V-ATPase are regulators of melanosomal $\mathrm{pH}$ homeostasis in zebrafish, providing a mechanism for human pigment evolution and disease. Pigment Cell Melanoma Res. 2013, 26, 205-217. [CrossRef]

29. Yan, X.; Wie, L.; Huang, J.; Wang, J.; Yang, Z.; Gan, B.; Liu, K.; Teng, Z.; Zhang, S.; Ye, X. Comparative skin transcriptome between common carp and the variety Jinbian carp (Cyprinus carpio v. jinbian). Aquac. Res. 2020, 51, 187-196. [CrossRef]

30. Le Guyader, S.; Maier, J.; Jesuthasan, S. Esrom, an ortholog of PAM (protein associated with c-myc), regulates pteridine synthesis in the zebrafish. Dev. Biol. 2005, 277, 378-386. [CrossRef]

(C) 2020 by the authors. Licensee MDPI, Basel, Switzerland. This article is an open access article distributed under the terms and conditions of the Creative Commons Attribution (CC BY) license (http://creativecommons.org/licenses/by/4.0/). 